\title{
Understanding the impact of isolation due to COVID-19 on employment for Kentuckians with spinal cord injuries
}

\author{
Chithra Adams*, Anthony Lobianco, Emily Moseley and Calisa Fitzpatrick \\ Human Development Institute, University of Kentucky, Lexington, KY, USA
}

Received 18 July 2020

Accepted 25 October 2020

\begin{abstract}
.
BACKGROUND: Obtaining and retaining employment for persons with spinal cord injury (SCI) is frequently a greater challenge than it is for the non-SCI population. It is particularly difficult during COVID-19 because all the barriers to employment are compounded for people with SCI as they have to take extra precaution to protect their health and wellbeing. OBJECTIVE: The objective of the study was to understand how isolation related to COVID-19 has had an effect on the employment experiences for persons living with SCI.

METHODS: Three virtual focus groups were conducted with Kentuckians who had SCI.

RESULTS: The major themes were: the impact of disruption in routine on physical and mental health, importance of having the right accommodations, working from home as an accommodation, and the uncertainty of work.

CONCLUSIONS: Accommodations are a critical component for people with SCI to be retained in the workforce. Employers should be proactive in offering various inclusive and accessible accommodations to employees so that people do not have to bear the additional burden of asking for accommodations. Rehabilitation professionals would serve the SCI population well by finding ways to help clients better advocate for themselves, provide adaptive home therapeutic equipment, and help identify diverse employment skill sets.
\end{abstract}

Keywords: COVID-19, spinal cord injury, employment, isolation

\section{Introduction}

Current estimates indicate that 288,000 persons in the United States are living with Spinal Cord Injury (SCI) and that there are 17,700 new cases of SCI per year (National SCI Statistical Center, 2018). PreCOVID, approximately one-third of persons with SCI reported engaging in some form of employment, far below the rate of labor force participation in the American general population (63\%, Bureau of Labor Statistics 2020).

\footnotetext{
*Address for correspondence: Chithra Adams, Human Development Institute, University of Kentucky, Lexington, KY 40506, USA. Tel.: +1 859218 0245; Fax: +1 859323 1901; E-mail:

Chithra.adams@uky.edu.
}

Gaining and retaining paid work has been shown to improve life satisfaction, quality of life and adjustment to life with SCI (Ottomaneli \& Lind, 2009).

Several researchers have identified factors that are predictive of employment for the SCI population. These include but are not limited to gender (males do better), race (Whites fare better), education, self-advocacy, pre-injury employment history, networking, physical health, level of injury and time since injury (Ottomanelli \& Lind, 2009, Inge et al., 2018). Other factors have been shown to have negative consequences for employment: disincentives related to the receipt of public benefits; lack of accommodations; discrimination; and lack of motivation (Inge et al., 2018; Marini et al., 2008). While many of these factors are static, others may be fluid and 
impacted by external conditions. The novel coronavirus, or COVID-19, drastically changed nearly every aspect of normal life beginning in early 2020 . In the general population, we know that employment among women was impacted more harshly than it was for men, that African-Americans were disproportionately affected, that feelings of isolation and depression dramatically increased, that routine healthcare was delayed, that disincentives toward employment grew due to both business closures and relief programs, and that our education system was disrupted at all levels. Nearly all of these factors align with the reasons listed above for lower employment for persons with SCI.

Other factors may offset some of these challenges for persons with SCI. The ability to work remotely and/or virtually is something that persons with SCI may have been more familiar with than the general population, which is now often forced to adapt to this work model. So too are persons with SCI likely to be used to rapid changes in life situations and to more readily adapt to shocks to the system, so to speak.

In this study, we set out to discover how persons with SCI were impacted by the onset of this global pandemic. Although our overall study probed deeply into many life areas, in this article we focus on how the experience of isolation related to COVID-19 has had an effect on experiences related to employment for persons living with SCI. The exploratory nature of the research question required a qualitative approach. A qualitative approach lends itself to understanding how the various contextual factors shape and influence a phenomenon (Conger, 1998).

\section{Method}

A series of focus groups were conducted to answer the research question. Focus groups allow for group interaction to explore insights collectively (Ho, 2006). The group interaction also allows for generation and sharing of perspectives that might not be shared in one on one interviews (Stewart \& Shamdasani, 1990). Three focus groups were conducted over a period of two weeks. The groups were conducted in late June 2020, almost 3 months after the start of the Coronavirus pandemic. On March 26, 2020, a 'Healthy at Home' executive order asking people to stay at home and limiting in-person contact was put in place in the Commonwealth of Kentucky. The order was concluded on June 30th, 2020. At the time of the focus groups, participants had stayed at home for almost 3 months but also were aware that the reopening was imminent.

The focus groups were conducted over Zoom, an online videoconference platform. Sessions were moderated by the Principal Investigator (PI). The PI brings nearly 30 years of lived experience as a quadriplegic and made this known to participants at the start of each focus group. He also has extensive training in qualitative analysis and moderating group discussions. The focus groups also had two facilitators for monitoring the chat feature in the video conference platform and for troubleshooting technology issues.

\subsection{Participants}

Participant recruitment was conducted through listservs. A message about the research study was sent to the Kentucky Congress for Spinal Cord Injury and the Kentucky Pilot State Paralysis Resource Center listservs. Participants who expressed interest were asked to complete a short screening questionnaire. The screening questionnaire described the purpose of the study; declared the study risks; and asked if the participants were 18 years of age or older, if they had a spinal cord injury, if they resided in Kentucky, if they were willing to participate in a focus group with four other participants, if they had internet access, if they had a device through which they could participate in a virtual focus group, and if they consented to being recorded as a part of the research protocol. Participants who answered 'Yes' to all the screening questions were then asked to select their preferences with regard to focus group dates and times. The first focus group session had five participants, the second focus group had six participants, and the third focus group had three participants. A total of 14 people participated in the research study. The study protocol was granted approval by the University Institutional Review Board. Participants were given an honorarium of $\$ 100$ to acknowledge their time and participation in the research study.

Table 1 provides a participant description.

\subsection{Data collection}

The focus groups were guided by a series of questions related to the COVID-19 pandemic. The question most relevant to this article was, "How has COVID-19 impacted employment for Kentuckians with spinal cord injuries?" 
Table 1

Participant description

\begin{tabular}{|c|c|c|c|c|}
\hline Pseudonyms* & $\begin{array}{l}\text { Male or } \\
\text { female }\end{array}$ & $\begin{array}{l}\text { Years since } \\
\text { injury }\end{array}$ & $\begin{array}{l}\text { Current } \\
\text { employment }\end{array}$ & $\begin{array}{l}\text { Living situation } \\
\text { during COVID }\end{array}$ \\
\hline Lindsey & $\mathrm{F}$ & 20 YRS & Job placement specialist & Lives with at least one other person (unspecified) \\
\hline Lavern & $\mathrm{F}$ & 8 YRS & Graphic designer & Lives with parents \\
\hline Sandy & $\mathrm{F}$ & 25 YRS & Public speaker (self-employed) & Lives with husband \\
\hline Hayden & M & 2 YRS & Student & Lives alone \\
\hline Addison & $\mathrm{F}$ & 16 YRS & Attorney & Lives with mom \\
\hline Odell & $\mathrm{F}$ & 31 YRS & Non-profit staff & Lives alone \\
\hline Campbell & $\mathrm{F}$ & & Self-employed & Lives with husband \\
\hline Kelly & $\mathrm{F}$ & $14.5 \mathrm{YRS}$ & Nonprofit staff and founder. & Lives alone \\
\hline Kamryn & $\mathrm{F}$ & 44 YRS & Retired technical writer; artist & Lives with husband \\
\hline Daly & $\mathrm{F}$ & & State coordinator for a non-profit & Lives alone \\
\hline Vinnie & M & $45+$ YRS & Works at government agency & Lives alone \\
\hline Sage & $\mathrm{F}$ & 20 YRS & Currently unemployed; looking for a job & Lives with mom and sister \\
\hline River & M & 27 YRS & Program coordinator & Lives with wife \\
\hline Coby & M & 38 YRS & Director at a non-profit & Lives with wife and father-in-law \\
\hline
\end{tabular}

*The pseudonyms were assigned using Random Name Generator (behindthename.com). The parameters set to generate the names were as follows: English, first name only, ambiguous, avoid rare names. Two participants did not disclose the number of years since post injury.

\subsection{Data analysis}

The focus group sessions were digitally recorded and transcribed. The digital interviews were transcribed verbatim and saved as a Microsoft Word file. Participants were given pseudonyms in the transcripts to reduce bias. As much as possible, the focus groups were transcribed within a few days after they were completed. The transcripts were checked against the audio files for accuracy. The Microsoft Word files were used for data analysis. An open coding process was done as a part of the initial coding. The open coding process allows the researcher(s) to keep an open mind and approach the data without predetermined categories and themes (Ezzy, 2002). The textual data were read multiple times by each researcher separately. As a part of the initial reading, the researcher wrote headings within the textual data. Headings were written in the text to describe and broadly sort the textual data (Hsieh \& Shannon 2005). After each review, the researchers convened to review the coding of the textual data. Categories were developed collectively. The categories were labeled and properties of the categories were identified. The categories were then again merged to create broader themes.

\section{Results}

Of the 14 participants, 11 were employed at the time of the focus group. Of the three participants who were not employed, one participant was unemployed and actively looking for work, one was a student, and another was retired. The participant who was unem- ployed lost her job due to the pandemic. Years since injury ranged from two years to 44 years. Of the 14 participants, four identified as male and 10 as female.

\subsection{Theme: Remote work changed routines necessary for physical health}

Participants discussed how their normal routines that came with going to work everyday were necessary to keep them in good health. Addison used a manual chair with e-motion wheels and she was pushing a lot when she was working at her office downtown. Because of remote work, Addison did not use her manual chair as much. River talked about how not going out and into a car was impacting his physical health. He said:

My physical health has kind of suffered a little bit from not getting out and getting into a car, going places. And my physical health, it's just been kind of like, it's messed with my sleeping routine. I'm really lucky that I've been able to work from home. But it's kind of caused a lot of I just feel a little more pain and things like that that I just noticed more and I think it's just because strictly because I' $m$ not in a regular routine of just kind of going out into the community and doing things which kind of help to keep me moving.

Prior to the pandemic, Addison had a routine that involved getting up early. She not only went to work but also had to go to a rehabilitation center. With the pandemic, her routine was disrupted and her health was impacted. She said: 
But now it's all sort of gone and I sleep really late and I stay up really late and don't have anything I have to do at a particular time of any day. I'm eating fewer meals, I realized, because my sleep schedule is changed.

Odell had considerations that required her to go away from the computer and move. Because of remote work, she was spending more time in front of the computer and had a skin breakdown. She remarked:

So, I'd be working at my computer for eight hours a day and then get done with job number one and then start working on job number two, three and four for the next four hours. So, I'd be putting in really long hours, and of course my butt broke down. That was part of it, you know, because at the office I'll go and run to the computer, pick something up, chat for a little bit. And so, you're just moving around a little bit more, where at home, you're just in front of the computer and you're not moving. So that was one aspect of physical health, though, that I did see an impact.

\subsection{Theme: Remote work presenting new mental health challenges}

As expected, participants talked about how remote work had required them to pivot from in person activities to virtual offerings, and this presented mental health challenges. Participants mentioned how they were experiencing 'Zoom fatigue'. While technology allowed participants to continue to do their work during the stay at home orders, it also created an environment wherein people were working on their computers for extended periods. For example, Vinnie said, "I just stayed at the computer too much. You know, I'm sitting here eating my lunch, sitting here taking a break, sitting here constantly focused on this." Odell mentioned, "In fact, there was almost more communication and more Zoom fatigue as a result of all of this." Coby, who has an outgoing personality, missed interacting with his coworkers and talking to people to help deal with the issues he was facing. Addison, who also has an outgoing personality and is a public speaker, also missed interacting with people and felt unmotivated to work. She said:

And I'm also super not motivated like, because I'm not seeing anybody, I guess. I don't have any motivation, though to get my work done like quickly or on time, which is aggravating to sev- eral people. I'm something like a little cocoon and I'm working on that.

\subsection{Theme: Importance of having the right accommodations and working from home as an accommodation}

Having the right accommodations influenced participants perception of working from home. For example, Lavern mentioned how she loved working from home because it completely fit her needs. Lindsey's employer delivered a table that positively changed her experience working from home. Before the pandemic, she did not have a customized table and working from home was not a good experience as she had a lot of pain in her neck and shoulders. Lindsey's employer also gave her a cell phone so she could make necessary client calls.

At the same time, participants noted that working from home was an important accommodation as it allowed people to work and be safe. River worried how long his employer might continue to accommodate him working from home. Lindsey was already working on paperwork asking to work from home as a reasonable accommodation; she could not risk working at an office building with many people. She remarked:

Well, I do have a fear of returning to the office just because I know how I am. When I get sick. I get very sick and I get very sick very quickly. So, if we were to go back into an office. I mean, we're in the office that I'm in, it has thousands of people in the building so that does cause me anxiety. So, I'm working on reasonable accommodation paperwork, just to make sure. They've not said that we're going back anytime soon. But I am going to go on and get that paperwork filled out just to protect myself so...

Addison and Lavern echoed Lindsey's anxiety about going to work and putting her health at risk. Lavern asked her employer for a modified work schedule, but she also noted that she felt uncomfortable asking for a special accommodation.

I did ask if I could come in on Tuesdays and Thursdays, and then work at home the rest of the days of the week, like Monday, Wednesday and Friday. I hate asking for special accommodations. It's really annoying because, you know, I want to be, feel normal and being treated normal (inaudible word) and not feel like my injury really 
controls my life or my ability to control my life. But then when it comes to circumstances like this, they do. I have to, you know, speak up. I have to defend my, not necessarily defend, but protect my immune system and because if I did get it, God forbid, you know, it could be pretty detrimental for my abilities. So that was really annoying, but I knew it was the right thing to do, to ask for those.

Addison felt guilty that she would need to rely on her co-workers to provide the personal support to her clients when her workplace was re-opened to regular working mode. For Addison to continue to work from home in the long run, she would need to re-arrange the services she provided for her clients. She said:

I don't feel like it's, you know, safe for me to be going into a big crowded building or you know, if there are, if I've got my issues or something and it's everybody else is involved in it is all good to go. And then I have to say, okay.

I know that you've already kind of gotten agreement with like seven other people for this time and date, but I'm going to need you to make a special exception for me. Because, you know, it wouldn't be just so bad if it was just my stuff. But I know that it's going to impact my clients and that makes me feel kind of guilty.

\subsection{Theme: Uncertainty of finding and keeping work}

Several employed participants mentioned how they were not sure if they would still have a job in the future. Some quotes are provided below.

"And I don't know if I can continue to work from home, we've been accommodated up to this point." (River)

"My place of employment, we are federally funded through grants... this continued downturn and... and lack of tax revenue will potentially impact my employment status." (Coby)

Sandy, who is a self-employed public speaker, mentioned how social distancing requirements had decreased her speaking opportunities. She said "One of the things that I had mentioned, I do a lot of public speaking and that is primarily in high schools, middle schools, churches, and all of those have been closed. So, it's just pretty much been nonexistent for that period of time."
Sage, a participant who is actively looking for work, had lost her temporary job because it had shut down due to COVID-19. She commented not only how jobs were hard to find but also that the job opportunities that were in her community were not suitable. Sage said:

So right now, the only thing hiring is like production and maintenance and stuff like that. So obviously being in a wheelchair, I can't do production or stuff like that, but I did have the temp agency called me for one job to be the temperature taker. And I was all lined up to do that. And then they realized that I would be going up and down steps so that ruled that out.

\section{Discussion}

There can be no doubt that the global pandemic related to COVID-19 has had a significant impact on virtually all members of society and in nearly every domain of people's lives. One of those domains is employment. Although our goal in this article was not to document every way in which the pandemic has affected employment for society at large, it should be noted that our target population, persons with SCI, encounter all of the same issues that the general population does in relation to employment due to the pandemic. People with SCI also confront disability-specific issues related to mobility, access to technology, and health maintenance that must be understood by vocational rehabilitation professionals. We used a qualitative inquiry approach to explore the factors that are unique to or exacerbated within the SCI population related to employment during the pandemic. The major themes of our findings included: the impact of disruption in routine on physical and mental health, the importance of having the right accommodations, working from home as an accommodation, and the uncertainty of work.

In terms of limitations, the study focused on individuals with SCI who are living in Kentucky. As restrictions and case counts have varied markedly from state to state, geographical locations might influence the isolation impact. As with many qualitative studies, there are limits to generalizability of the findings due to the non-random sampling procedure.

Obtaining and retaining employment for persons with SCI is frequently a greater challenge than it is for the non-SCI population even in normal times (Ottomanelli \& Lind 2009). The desire to keep their jobs for persons in our sample who were employed, 
as well as the fear of losing their jobs, cannot be overstated. Many participants spoke to the need for accommodations such as working from home during this time, and the need to work from home even after their workplaces re-opened to on-site work. The Job Accommodation Network is an excellent resource for individuals to identify what kinds of accommodations are necessary within the realm of applicable laws and provides advice on how to ask for reasonable accommodations (www.askjan.org, Job Accommodation Network website).

Another major issue raised by several of our participants involved feelings of guilt over asking for accommodations. During a period of heightened unemployment, it may be the case that individuals think of their jobs as more expendable, and thus do not want to be seen as someone who needs "one more accommodation." Most respondents spoke highly of their employer's willingness to provide accommodations, so a larger issue may be psychological in nature rather than pragmatic or legal. Similarly, respondents noted feelings of guilt related to requesting assistance from fellow employees, as well as the ability to remain flexible for clients. These feelings speak to the mental and emotional toll of living through a pandemic with a spinal cord injury, and the need for a more holistic approach toward ongoing rehabilitation that addresses not only the physical needs but the psychosocial well-being of individuals with SCI. Employers and vocational rehabilitation professionals should consider working remotely and related technology (to the extent possible) as a universal design strategy for their employees and clients.

Even when accommodations were available (as they almost always were) for individuals to work remotely, many participants indicated the negative consequences of changing their routines in this way. Things as simple as not pushing one's manual wheelchair further, both within the office and to get to one's place of business, caused muscle weakness among some respondents. Others noted that the lack of regular movement caused skin breakdown. Respondents noted disruptions in sleep patterns leading to the inability to concentrate. For a person without SCI these may well all be issues worthy of discussion as well. However, solutions are far more readily available in the absence of SCI. Home exercise equipment sales have exploded during the pandemic, however for a person with limited mobility who may require adaptive equipment or consultation with therapists, such equipment may not be as available. Stagnation, monotony, and lack of motivation are issues faced by many in our society. However, the results of such factors can be catastrophic for a person with SCI. Vocational rehabilitation strategies for persons with SCI often focus on maintaining routines in one's activities of daily life. When these routines cannot be maintained, quality-of-life suffers. A greater focus on how to deal with abrupt changes to routines may be able to mitigate some of the difficulties described above.

The need to move into different areas of employment was noted by respondents. Abrupt changes in the labor market disadvantage those with less diverse skill sets. The presence of SCI makes the acquisition of many jobs nearly impossible. A person with an SCI may be a vibrant public speaker, but when opportunities for public speaking dry up they may not be able to shift into positions that require manual labor. This creates a disparate impact between people with and without SCI. Some respondents noted that they currently work in the public sector, and as public revenue decreases over time they may have limited opportunities for the type of employment for which they have been trained. Even without a global pandemic it will always be the case that workforce needs change over time. Specialists in rehabilitation and employment might be wise to prepare clients for a multitude of diverse employment outcomes (Cooney, 2016; Lindstrom, Doren, Post, \& Lombardi, 2013).

Of course, one of the biggest fears during this time for everyone is contracting COVID-19. Many in our sample noted this in relation to employment and employment prospects. As individuals return to on-site work, greater risks of COVID-19 exposure are the reality for everyone. However, for persons with SCI, risks may be greater. Reduced lung function, compromised immunity, and the inability to detect subtle changes in much of one's body all create a greater potential for the acquisition and prognosis of someone with SCI who contracts COVID-19 (LopezDolado \& Gil-Agudo, 2020). Nearly all persons with SCI have extensive experience with the medical system, and often this experience is not positive. When faced with the risk of fully engaging with others, be it in a workplace setting or elsewhere, persons with SCI including those in our sample have expressed reluctance to do so. Part of this issue reverts to the need for accommodations, and in particular the ability to work remotely. While persons with SCI need to be more vocal advocates for these accommodations, employers should also understand the gravity of contracting a serious disease for a person with a spinal cord injury. 
There is no simple solution for improving the employment experiences for persons with SCI during a pandemic. Accommodations are a major piece of the puzzle, but our research leads us to believe that the lack of accommodations is as much due to emotional factors on the part of the person with SCI than it is with legal or employment issues. Rehabilitation professionals would serve the SCI population well by finding a way to help clients better advocate for themselves, accommodate adaptive therapeutic equipment for the home, and provide for a more diverse skill set related to employment.

\section{Conflict of interest}

None to report.

\section{References}

Bureau of Labor Statistics. (2020). Civilian labor force participation rate. U.S. Department of Labor, Bureau of Labor Statistics. Retrieved from https://www.bls.gov/charts/employmentsituation/civilian-labor-force-participation-rate.htm

Conger, J. A. (1998). Qualitative research as the cornerstone methodology for understanding leadership. The Leadership Quarterly, 9(1), 107-121. https://doi.org/10.1016/S10489843(98)90044-3

Cooney, K. (2016). Work Integration Social Enterprises in the United States: Operating at the Nexus of Public Policy, Markets, and Community. Nonprofit Policy Forum, 7(4), 435-460. https://doi-org.ezproxy.uky.edu/10.1515/npf-2016-0009
Ezzy, D. (2002). Qualitative analysis: Practice and innovation. Allen \& Unwin.

Ho, D. G. (2006). The focus group interview: Rising to the challenge in qualitative research methodology. Australian Review of Applied Linguistics, 29(1), 5-1.

Hsieh H.-F. \& Shannon S. (2005) Three approaches to qualitative content analysis. Qualitative Health Research, 15, 1277-1288. https://doi.org/10.1177/1049732305276687

Inge, K. J., Bogenschutz, M. D., Erickson, D., Graham, C. W., Wehman, P., \& Seward, H. (2018). Barriers and facilitators to employment: As reported by individuals with spinal cord injuries. Journal of Rehabilitation, 84(2), 22-32.

Job Accommodation Network. Retrieved from https://askjan.org/

Lindstrom, L., Doren, B., Post, C., \& Lombardi, A. (2013). Building Career PATHS (Postschool Achievement Through Higher Skills) for young women with disabilities. Career Development Quarterly, 61(4), 330-338. https://doi.org/10.1002/j.21610045.2013.00059.x

López-Dolado, E., \& Gil-Agudo, A. (2020). Lessons learned from the coronavirus disease 2019 (Covid-19) outbreak in a monographic center for spinal cord injury. Spinal cord, 58(5), 517-519. https://doi.org/10.1038/s41393-020-0473-Z

Marini, I., Lee, G. K., Chan, F., Chapin, M. H., \& Romero, M. G. (2008). Vocational rehabilitation service patterns related to successful competitive employment outcomes of persons with spinal cord injury. Journal of Vocational Rehabilitation, 28(1), $1-13$.

Ottomanelli, L., \& Lind, L. (2009). Review of critical factors related to employment after spinal cord injury: implications for research and vocational services. The Journal of Spinal Cord Medicine, 32(5), 503-531. https://doi.org/ 10.1080/10790268.2009.11754553

Stewart, D. W., \& Shamdasani, P. N. (1990). Focus groups: Theory and practice. Sage. 